\title{
Pengaruh Temperatur dan Waktu Putar Terhadap Sifat Optik Lapisan Tipis ZnO yang Dibuat dengan Metode Sol-Gel Spin Coating
}

\author{
Fitriani $^{*}$, Sri Handani * \\ Laboratorium Fisika Material, Jurusan Fisika, FMIPA, Universitas Andalas \\ Kampus Unand, Limau Manis, Padang, 25163 \\ *fitriania1010@gmail.com,*shandani69@yahoo.com
}

\begin{abstract}
ABSTRAK
Penelitian tentang pengaruh temperatur dan waktu putar terhadap sifat optik lapisan tipis $\mathrm{ZnO}$ yang dibuat dengan metode sol-gel spin coating telah dilakukan. Penelitian dilakukan dengan variasi suhu $400^{\circ} \mathrm{C}, 500^{\circ} \mathrm{C}$ dan $600^{\circ} \mathrm{C}$ dengan waktu putar 4 menit dan 6 menit pada kecepatan $2000 \mathrm{rpm}$. Uji UV-Vis dan XRD digunakan untuk mempelajari sifat optik dan struktur. Nilai minimum bandgap sebesar 5,5 eV diperoleh pada lapisan tipis yang dideposisi dengan waktu putar 6 menit dan suhu annealing $600^{\circ} \mathrm{C}$ Karakterisasi UV-Vis menunjukkan absorbsi paling besar 0,944 diperoleh pada lapisan tipis yang terdeposisi dengan waktu putar 4 menit dan suhu annealing $400^{\circ} \mathrm{C}$, Hasil XRD yang menunjukkan penambahan suhu menyebabkan menurunnya ukuran kristal.
\end{abstract}

Kata kunci : sol gel spin coating dan bandgap.

\section{ABSTRACT}

The research on the effect temperature and spin time to the optical properties of ZnO thin layer made by sol-gel spin coating method has been done. The research is conducted at temperature variations of $400^{\circ} \mathrm{C}, 500^{\circ} \mathrm{C}$ and $600^{\circ} \mathrm{C}$ with 4 minutes and 6 minutes spinning time at speed of $200 \mathrm{rpm}$. UV-Vis and XRD techniques have been used to investigate the optical properties and structure. The minimum bandgap is $5.5 \mathrm{eV}$ from thin film that deposited at $600 \mathrm{oC}$ with 6 minutes spinning time. UV-Vis characteristic show that biggest absorption is 0.944 from $\mathrm{ZnO}$ thin film that deposited at $400^{\circ} \mathrm{C}$ with 4 minutes spinning time. XRD results indicates that the increase of temperature causes the decrease of the crystal size.

Keyword: sol gel spin coating and bandgap.

\section{PENDAHULUAN}

Material semikonduktor $\mathrm{ZnO}$ menjadi pusat perhatian para peneliti baik di bidang industri maupun teknologi. Hal ini disebabkan material $\mathrm{ZnO}$ mempunyai sifat yang menarik dan aplikasi yang luas. Material semikonduktor ini mempunyai beberapa sifat yang menguntungkan seperti : mempunyai daya tembus yang baik, mobilitas elektron yang tinggi, bandgap (celah pita) yang lebar, tahan pada temperatur tinggi, dapat memendarkan cahaya dan sebagainya. Terkait dengan sifat-sifatnya tersebut, material $\mathrm{ZnO}$ telah diteliti dan dipelajari secara luas untuk aplikasi sensor gas ( Musat, 2008 ), LED dan elektroda transparan ( Kwak, 2008 ).

$\mathrm{ZnO}$ dalam bentuk nanopartikel ataupun lapisan tipis dapat dengan mudah disintesis menggunakan metode yang sederhana (tanpa proses sublimasi keadaan vakum) dan temperatur relatif rendah dibandingkan dengan jenis logam lainnya (Musat, 2008). Beberapa jenis metode sintesis $\mathrm{ZnO}$ berstruktur nano adalah chemical vapor deposition (CVD), metal-organic CVD, elektrodeposisi, solution process termasuk metode sol-gel ( Jain, 2005 ).

Sol-gel spin coating adalah metode untuk membuat lapisan dari bahan polimer photoresist yang dideposisikan pada permukaan silikon dan material lain yang berbentuk datar. Setelah larutan (sol-gel) diteteskan di atas subtrat, kecepatan putar diatur oleh gaya sentrifugal untuk menghasilkan lapisan tipis yang homogen. Metode sol-gel spin coating ini menggabungkan metode fisika dan kimia biasa. Metode ini sangat mudah dan efektif untuk membuat lapisan tipis dengan hanya mengatur parameter waktu dan kecepatan putar serta viskositas larutan.

Pada penelitian ini, dibuat lapisan tipis $\mathrm{ZnO}$ menggunakan metode sol-gel spin coating dengan variasi temperatur dan waktu putar. Dengan metode ini diharapkan lapisan tipis yang dihasilkan homogen dan transparan. 


\section{METODE}

\subsection{Pembuatan pasta $\mathrm{ZnO}$ (Zinc Oxide)}

Dalam pembuatan pasta ZnO (Zinc Oxide), PVA (Polyvinyl Alcohol) dengan massa 0,3 gram ditambahkan kedalam $4 \mathrm{~mL}$ aquades, kemudian diaduk selama 60 menit pada suhu $400^{\circ} \mathrm{C}$,. yang akan berfungsi sebagai binder dalam pembuatan pasta. Suspensi dicampurkan dengan 3 tetes asam asetat $25 \%$ dan ditambahkan bubuk $\mathrm{ZnO}$ (Zinc Oxide) 0,3 gram. Campuran suspensi dan bubuk $\mathrm{ZnO}$ (Zinc Oxide) diaduk selama 60 menit menggunakan magnetic stirer sampai didapatkan pasta yang baik untuk dilapisi pada substrat. Setelah itu, pasta $\mathrm{ZnO}$ (Zinc Oxide) disonikasi selama 10 menit untuk menghomogenkan partikel ZnO.

\subsection{Penumbuhan $\mathrm{ZnO}$ (Zinc Oxide)}

Penumbuhan ZnO pada subtrat kaca FTO (Fluorine Tin Oxide) dimulai dengan menempatkan subtrat FTO yang sudah dibersihkan di atas piringan spin coater dengan area deposisi pasta $\mathrm{ZnO}$ seperti Gambar 1. Penumbuhan pasta $\mathrm{ZnO}$ pada subtrat FTO menggunakan metode dispensi statis pada kecepatan 2000 rpm dengan variasi waktu 4 menit dan 6 menit

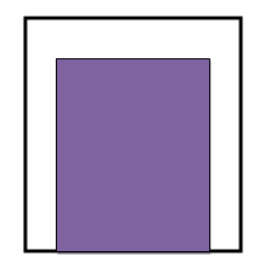

Gambar 1 Ilustrasi daerah deposisi pasta $\mathrm{ZnO}$

\subsection{Prose pemanasan (Heating)}

Substrat yang telah dilapisi dengan pasta $\mathrm{ZnO}$ dipanaskan selama 10 menit pada suhu $400^{\circ} \mathrm{C}, 500^{\circ} \mathrm{C}$ dan $600^{\circ} \mathrm{C}$, proses pemanasan ini berfungsi untuk menumbuhkan kristal $\mathrm{ZnO}$ pada lapisan tipis tersebut.

\subsection{Karakterisasi Sampel ZnO}

Karakterisasi $X$-ray diffraction (XRD) bertujuan untuk mengetahui struktur dan ukuran kristal lapisan tipis $\mathrm{ZnO}$ yang terdeposisi dengan metode sol-gel spin coating. Karakterisasi $\mathrm{UV}-\mathrm{Vis}$ bertujuan untuk mengetahui sifat optik lapisan tipis $\mathrm{ZnO}$ yang terdeposisi dengan metode sol-gel spin coating.

\section{HASIL DAN DISKUSI}

\subsection{Karakterisasi UV-Vis}

Karakterisasi spektroskopis UV-Vis dilakukan untuk mengetahui tingkat absorbsi lapisan tipis $\mathrm{ZnO}$ untuk masing-masing suhu pemanasan dan waktu putar. Selain itu dapat juga ditentukan nilai energi gap pada masing-masing sampel. Kurva serapan untuk enam buah sampel yang dikarakterisasi dengan UV-Vis dan hasilnya menunjukkan sampel mempunyai serapan dari panjang gelombang $208 \mathrm{~nm}$ sampai $300 \mathrm{~nm}$. Nilai serapan minimum ditunjukkan oleh sampel pada suhu $500^{\circ} \mathrm{C}$ dengan waktu empat menit pada panjang gelombang $254,05 \mathrm{~nm}$ yaitu 0,198 dan penyerapan maksimum ditunjukkan oleh sampel pada suhu $400^{\circ} \mathrm{C}$ dengan waktu enam menit pada panjang gelombang 208,22 nm sebesar 0,944. Berdasarkan nilai absorbansi yang terbaca untuk seluruh sampel merupakan rentang panjang gelombang ultraviolet. Berikut spektrum absorbsi lapisan tipis $\mathrm{ZnO}$ yang terbentuk. 

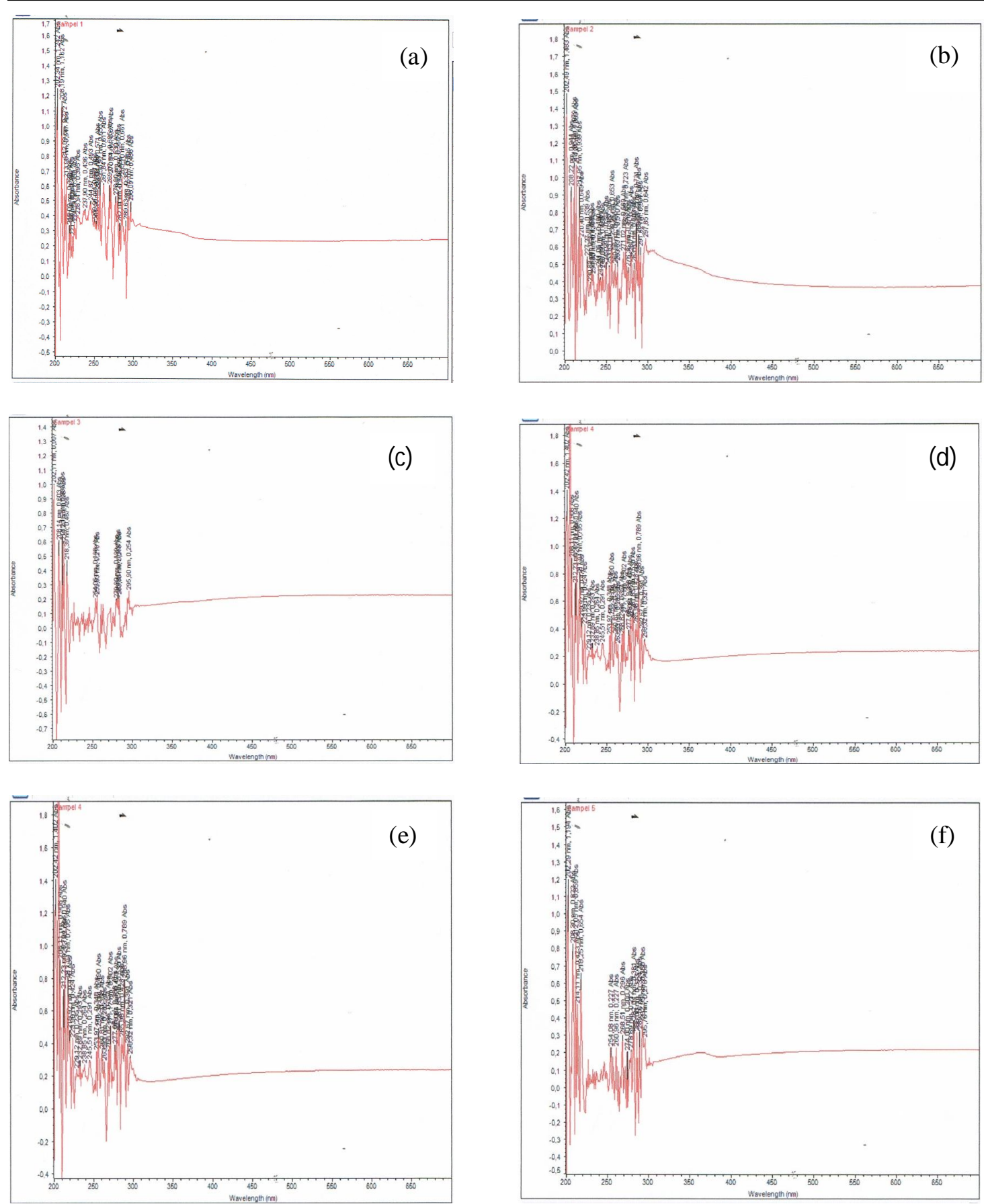

Gambar 2 Grafik hasil UV-Vis variasi suhu dan waktu putar spin coater (a) $400^{\circ} \mathrm{C}, 4$ menit (b) $400^{\circ} \mathrm{C}, 6$ menit, (c) $500^{\circ} \mathrm{C}, 4$ menit, (d) $500^{\circ} \mathrm{C}, 6$ menit, (e) $600^{\circ} \mathrm{C}, 4$ menit, (f) $600^{\circ} \mathrm{C}$, 6 menit.

Hasil dari karakterisasi keseluruhan lapisan tipis $\mathrm{ZnO}$ menunjukkan absorbsi panjang gelombang yang berbeda pada perlakuan variasi suhu dan waktu putar spin coater. Panjang gelombang yang mampu diserap oleh lapisan tipis harus bersesuaian dengan band gap lapisan tipis tersebut, karena foton yang datang harus memiliki energi yang sama atau besar dari pada band gap yang dimiliki lapisan tipis $\mathrm{ZnO}$. Lapisan tipis yang dihasilkan dengan metode ini hanya mampu menyerap cahaya UV dengan rentang panjang gelombang 208,22 nm sampai $297,85 \mathrm{~nm}$. 


\subsection{Karakterisasi XRD}

\subsubsection{Analisis sampel dengan suhu $400^{\circ} \mathrm{C}$}

Hasil karakterisasi XRD sampel dengan suhu $400^{\circ} \mathrm{C}$ menghasilkan empat puncak difraksi seperti yang terlihat pada Gambar 3. Setiap puncak yang dihasilkan memiliki nilai intensitas yang berbeda terhadap posisi $2 \theta$ yang berbeda. Intensitas tertinggi berada pada posisi $2 \theta 36,08600$ yaitu sebesar 100 dan intensitas terendah sebesar 22,35 berada pada posisi $2 \theta$ 56,54420 . Kristalin yang kecil akan menghasilkan puncak difraksi yang lebar karena kristalin yang kecil memiliki bidang pantul sinar-X yang terbatas.

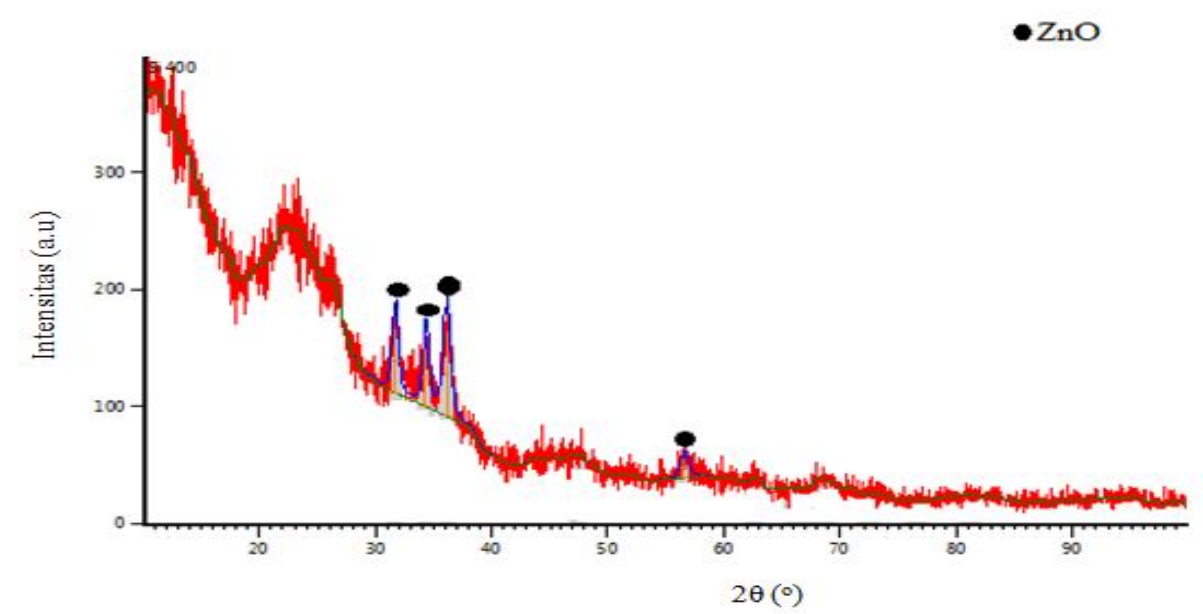

Gambar 3 Hasil karakterisasi XRD pada suhu $400^{\circ} \mathrm{C}$

Tabel 1 Nilai $2 \theta$ dan puncak tertinggi kurva XRD sampel suhu $400^{\circ} \mathrm{C}$

\begin{tabular}{cccc}
\hline Puncak & $\mathbf{2 \theta}$ & Intensit & FWH \\
\hline 1 & 31,6609 & 75,21 & 0,6140 \\
2 & 34,3246 & 67,60 & 0,6140 \\
3 & 36,0860 & 100,00 & 0,7164 \\
4 & 56,5442 & 22,35 & 0,8187
\end{tabular}

Berdasarkan data JCPDS no 010790208 struktur kristal yang dihasilkan pada suhu 400 ${ }^{\circ} \mathrm{C}$ dengan waktu 4 menit berbentuk wurtzite dengan parameter kisi $a=3,2648 \AA, b=3,2648 \AA$ dan $c=5,2194 \AA$. Struktur wurtzite merupakan struktur $\mathrm{ZnO}$ yang paling stabil (Patnaik, 2003; Sayono dan Sudjidno, 2008).

\subsubsection{Analisis Sampel dengan suhu $600^{\circ} \mathrm{C}$}

Hasil karakterisasi XRD sampel dengan suhu $600^{\circ} \mathrm{C}$ menghasilkan lima puncak difraksi seperti yang terlihat pada Gambar 4. Setiap puncak yang dihasilkan memiliki nilai intensitas yang berbeda terhadap posisi $2 \theta$ yang berbeda. Intensitas tertinggi berada pada posisi $2 \theta$ yaitu 26,56200 yaitu sebesar 100 dan intensitas terendah sebesar 19,73 berada pada posisi $2 \theta$ 56,64120 .

Hasil karakterisasi XRD sampel dengan suhu $600^{\circ} \mathrm{C}$ menghasilkan lima puncak difraksi seperti yang terlihat pada Gambar 4. Setiap puncak yang dihasilkan memiliki nilai intensitas yang berbeda terhadap posisi $2 \theta$ yang berbeda. Intensitas tertinggi berada pada posisi $2 \theta$ yaitu 26,56200 yaitu sebesar 100 dan intensitas terendah sebesar 19,73 berada pada posisi $2 \theta$ 56,64120 . 


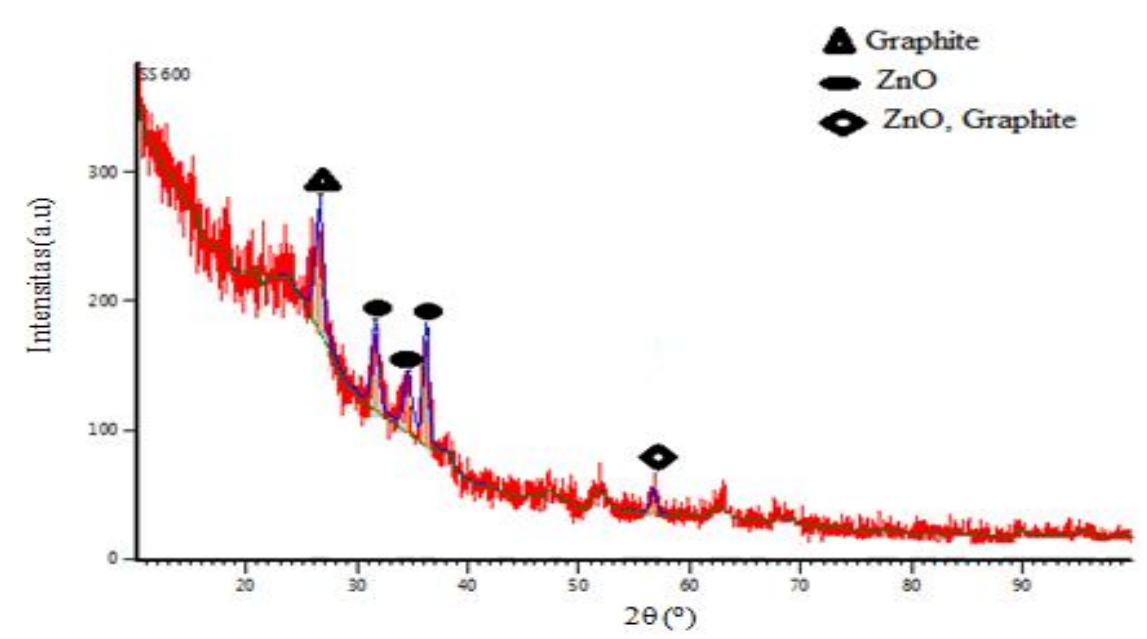

Gambar 4 Hasil karakterisasi XRD pada suhu $600^{\circ} \mathrm{C}$

Tabel 2 Nilai $2 \theta$ dan puncak tertinggi kurva XRD sampel suhu $600^{\circ} \mathrm{C}$

\begin{tabular}{cccc}
\hline Puncak & $\mathbf{2 \theta}$ & Intensitas & FWHM \\
\hline 1 & 26,5620 & 100,00 & 0,8187 \\
2 & 31,5981 & 64,01 & 0,7164 \\
3 & 34,5583 & 43,73 & 0,8181 \\
4 & 36,1843 & 95,66 & 0,5117 \\
5 & 56,6412 & 19,73 & 0,6140 \\
\hline
\end{tabular}

Tinggi rendahnya intensitas yang tertangkap detektor itu dipengaruhi oleh keteraturan susunan atom pada kristal tersebut. Semakin tinggi intensitas yang tertangkap oleh detektor menunjukkan bahwa susunan atomnya semakin teratur. Hasil dari kedua sampel yang dikarakterisasi dengan XRD menunjukkan bahwa sampel ini memiliki intensitas tertinggi sebesar 100. Struktur yang dihasilkan pada suhu $600 \mathrm{oC}$ dengan waktu 4 menit juga berbentuk wurtzite dengan parameter kisi $\mathrm{a}=3,2522 \AA, \mathrm{b}=3,522 \AA$ dan $\mathrm{c}=5,2095 \AA$.

Tabel 3 Ukuran kristal lapisan tipis $\mathrm{ZnO}$

\begin{tabular}{cc}
\hline Suhu & Ukuran Kristal \\
\hline $400^{\circ} \mathrm{C}$ & $24,294 \mathrm{~nm}$ \\
$600^{\circ} \mathrm{C}$ & $20,344 \mathrm{~nm}$
\end{tabular}

Berdasarkan Tabel 3 dapat dilihat bahwa ukuran kristal masing-masing suhu berbeda. Pada suhu $400^{\circ} \mathrm{C}$ didapatkan ukuran kristal sebesar $24,294 \mathrm{~nm}$ dan pada suhu $600^{\circ} \mathrm{C}$ ukuran kristal sebesar 20,344 nm. Peningkatan temperatur pemanasan menyebabkan ukuran kristal semakin kecil.

\section{KESIMPULAN}

Sampel lapisan tipis semikonduktor $\mathrm{ZnO}$ yang telah dikarakterisasi dengan UV-Vis menghasilkan serapan dari panjang gelombang $208 \mathrm{~nm}$ - $298 \mathrm{~nm}$ yang merupakan rentang panjang gelombang yang dimiliki sinar ultraviolet. Hasil karakterisasi XRD menunjukkan sampel pada suhu $600^{\circ} \mathrm{C}$ dengan waktu 6 menit memiliki bandgap minimum yaitu 5,5 e $\theta \mathrm{V}$. Hasil karakterisasi XRD untuk sampel $400^{\circ} \mathrm{C}$ dan $600^{\circ} \mathrm{C}$ menunjukkan perubahan ukuran kristal yang semakin kecil dengan bertambahnya suhu pemanasan.

\section{DAFTAR PUSTAKA}

Abdullah, M., 2009, Distribusi Celah Pita Energi Titanium Kotor, Prosiding, FMIPA, ITB 
Adnan, S.R, 2012, Proses Pembuatan dan Karakterisasi Lapisan Tipis Barium Zirkonium Titanat $\left(\mathrm{BaZr}_{\mathrm{x}} \mathrm{Ti}_{1-\mathrm{x}} \mathrm{O}_{3}\right)$ yang Didoping Lantanum dengan Metode Sol Gel, Skripsi, FMIPA, UI, Depok.

Aprilia, A., Bahar, H., dan Hidayat, R., 2010, Preparasi Lapisan Tipis ZnO Transparan Menggunakan Metode Sol-gel Beserta Karakterisasi Sifat Optiknya, Prosiding, ISBN 978-979-98010-6-7, FMIPA, ITB.

Arief, M, 2011, Sintesis dan Karakterisasi Nanopartikel Seng Oksida (ZnO) dengan Metode Proses Pengendapan Kimia Basah dan Hidrotermal untuk Alikasi Fotokatalis, Skripsi, Fakultas Teknik, UI, Depok.

Beiser, A., 1987, Konsep Fisika Modern Edisi Keempat, Erlangga, Jakarta.

Bilalodin, 2012, Pembuatan dan Penentuan Celah Pita Optik Film Tipis $\mathrm{TiO}_{2}$, Jurnal Nanosains dan Nanoteknologi, ISSN 0853-0823, Program Studi Fisika,Universitas Jenderal Soedirman.

Jain A, dkk, 2005, Materials Science Poland, Vol. 25.No 1.

Kittel, C., 2005, Introduction to Solid State Physics Eight Edition, John Wiley \& Sons, Inc., United States of America.

Kwak, H., 2008, Solid State Communication 145 : 227-230.

Maddu, A., 2006, Struktur dan Sifat Optik Film ZnO Hasil Deposisi Dengan Teknik SpinCoating Melalui Proses Sol-Gel, Jurnal Sains Material Indonesia, Vol. 7 No 3, hal 8590, FMIPA, IPB.

Musat,dkk, 2008, Thin Solid Films 516 1512-1515.

Patnaik, P., 2003, Handbook of Inorganic Chemicals, McGraw-Hill, New York. 